\title{
Combination of wogonin and sorafenib effectively kills human hepatocellular carcinoma cells through apoptosis potentiation and autophagy inhibition
}

\author{
LI-WEN RONG ${ }^{1,2}$, RUI-XUE WANG ${ }^{1}$, XUE-LIAN ZHENG ${ }^{1}$, XU-QIN FENG ${ }^{2}$, \\ LEI ZHANG ${ }^{1}$, LIN ZHANG ${ }^{1,3}$, YONG LIN ${ }^{1}$, ZHI-PING LI $^{2}$ and XIA WANG ${ }^{1,3}$ \\ ${ }^{1}$ Laboratory of Molecular and Translational Medicine, Key Laboratory of Birth Defects and Related Diseases \\ of Women and Children of Ministry of Education, Department of Obstetrics and Gynecology, \\ West China Second University Hospital; ${ }^{2}$ Department of Abdominal Oncology, Cancer Center, West China Hospital; \\ ${ }^{3}$ Department of Immunology, West China School of Preclinical and Forensic Medicine, \\ Sichuan University, Chengdu, Sichuan 610041, P.R. China
}

Received November 2, 2015; Accepted March 21, 2017

DOI: $10.3892 / 01.2017 .6059$

\begin{abstract}
The small molecule multi-kinase inhibitor sorafenib has become the standard systemic treatment for patients with advanced hepatocellular carcinoma (HCC) and renal cell carcinoma. Similar to other kinase inhibitors, drug resistance hinders its clinical use; thus, combination therapy to improve sorafenib sensitivity is a promising approach. The present study shows for the first time that the combination of sorafenib and wogonin exerts a significant potentiation of cytotoxicity in a number of human HCC cell lines in a dose-dependent manner. Enhanced cell death was due to potentiation of apoptosis, which was demonstrated by increased apoptotic cell populations, caspase activation and suppression of cell death by the pan-caspase inhibitor carbobenzoxy-valyl-alanyl-aspartyl. Sorafenib induced autophagy activation, which was shown by autophagic flux. Suppression of autophagy with the autophagy inhibitors chloroquine or 3-methyladenine significantly enhanced cytotoxicity, suggesting that sorafenib-induced autophagy is cytoprotective. Notably, wogonin effectively inhibited sorafenib-induced autophagy. Altogether, our results
\end{abstract}

Correspondence to: Professor Xia Wang, Laboratory of Molecular and Translational Medicine, Key Laboratory of Birth Defects and Related Diseases of Women and Children of Ministry of Education, Department of Obstetrics and Gynecology, West China Second University Hospital, Sichuan University, 20 Renminnanlu San Duan, Chengdu, Sichuan 610041, P.R. China

E-mail: xiawang@scu.edu.cn

Dr Zhi-Ping Li, Department of Abdominal Oncology, Cancer Center, West China Hospital, Sichuan University, 37 Guo Xue Xiang, Chengdu, Sichuan 610041, P.R. China

E-mail: lizhiping620312@163.com

Key words: autophagy, wogonin, sorafenib, apoptosis, HCC, drug resistance, synergy indicate that the combination of wogonin and sorafenib effectively kills human HCC cells. This occurs, at least in part, through autophagy inhibition, which potentiates apoptosis. Thus, wogonin could be an ideal candidate for increasing sorafenib's activity in HCC therapy, which warrants further investigation in vivo.

\section{Introduction}

The small molecule multi-kinase inhibitor sorafenib, a Food \& Drug Administration-approved oral agent for the treatment of hepatocellular carcinoma (HCC) and renal cell carcinoma, was originally developed as an inhibitor of Raf kinases, including c-Raf kinase, wild-type and mutant B-Raf, and the essential serine/threonine kinase constituents of the Ras/Raf/mitogen-activated protein kinase pathway (1). In addition to its effect on Raf proteins, sorafenib also potently inhibits receptor tyrosine kinases, including vascular endothelial growth factor receptors -2 and -3 and the platelet-derived growth factor receptor $\beta$ (2). Sorafenib has been shown to exert antitumor activity through inhibiting tumor cell proliferation and tumor angiogenesis, which is likely due to its effects on these multiple targets (2). Sorafenib treatment resulted in 3 -month extension of survival in advanced HCC patients in two placebo-controlled phase III studies $(3,4)$. Another phase III study in advanced HCC also demonstrated a significant improvement in progression-free survival relative to placebo (167 vs. 84 days, respectively) (5). However, considerable unresponsiveness or acquired resistance to sorafenib are commonly observed in HCC patients $(6,7)$, the precise mechanism of which is largely elusive. Thus, there is an increasing interest in defining the molecular mechanisms underlying sorafenib resistance in order to increase sorafenib's efficacy and overcome resistance in patients.

Autophagy is an important cellular process in response to cellular stresses to maintain proper cell function and survival (8). Numerous studies have shed light on the importance of autophagy in tumorigenesis, tumor proliferation and 
response to chemotherapy (9). Depending on the cellular context and the strength and duration of the stimulus, autophagy can either promote or inhibit cancer cell survival (10). Consistently, autophagy can promote or suppress apoptosis. As regard to response to chemotherapy, autophagy may mediate apoptosis to kill cancer cells or suppress apoptosis to contribute to chemoresistance in different circumstances. Thus, the manipulation of autophagy could be a useful strategy to improve the anticancer activity of therapeutics $(11,12)$. Previous studies revealed that sorafenib is able to activate autophagy, which may confer a survival advantage to cancer cells and lead to sorafenib resistance. By contrast, inhibiting autophagy was shown to promote sorafenib-induced cell death and increase its anticancer effect (13-15). A cell death-promoting role of sorafenib-induced autophagy has also been reported by several groups (16-18). Therefore, the precise role of autophagy in sorafenib-induced cell death requires to be elucidated.

In an effort to increase sorafenib's effects, one promising strategy is to combine sorafenib with other anticancer reagents $(19,20)$. However, the outcomes of several of these studies were not desirable due to safety concerns or not achieving the expected end point such as improved overall survival $(21,22)$. Thus, it is important to identify agents that can be used in combination with sorafenib. Multiple naturally occurring compounds from diets or medicinal plants can modulate different cellular survival pathways, thus potentiating the anticancer activity of drugs used in anticancer therapy $(23,24)$. One of such compounds is wogonin $(5,7-d i h y-$ droxy-8-methoxyflavone), a flavonoid derived from the root of the medicinal herb Scutellaria baicalensis Georgi (25). Wogonin has been shown to have antioxidant, antiviral, antithrombotic and anti-inflammatory activities in both in vitro and in vivo studies (26-29). The anticancer activity of wogonin is demonstrated by inducing apoptosis in cancer cells and suppressing growth of human cancer xenografts in vivo $(30,31)$. Wogonin has also been tested to kill cancer cells in combination with other chemotherapeutics $(32,33)$. However, the effect of wogonin in combination with sorafenib has never been reported. Therefore, the present study was designed to investigate whether the combination of sorafenib and wogonin is able to increase the anticancer activity of sorafenib in HCC cells and to elucidate the underlying mechanism. To the best of our knowledge, the present study is the first report showing that the combination of wogonin and sorafenib results in a synergistic cytotoxicity in HCC cells, which occurs through enhancing apoptosis and inhibiting autophagy.

\section{Materials and methods}

Reagents. Sorafenib (Nexavar) and wogonin were purchased from Bayer AG (Leverkusen, Germany) and Sigma-Aldrich (Merck Millipore, Darmstadt, Germany), respectively. Antibodies against poly (ADP-ribose) polymerase (PARP) (catalog no. 556494) and p62 (catalog no. 610832) were acquired from BD Biosciences (Franklin Lakes, NJ, USA). Anti- $\beta$-actin (catalog no. 60008-1-Ig) and anti-light chain 3 (LC3)B antibodies (catalog no. L7543) were obtained from ProteinTech Group, Inc. (Chicago, IL, USA) and Sigma-Aldrich (Merck Millipore), respectively. Chloroquine (CQ) and 3-methyladenine (3-MA) were purchased from Sigma-Aldrich (Merck Millipore). The pan-caspase inhibitor carbobenzoxy-valyl-alanyl-aspartyl (Z-VAD) was obtained from Calbiochem (Merck Millipore).

Cell lines and cell culture. The human HCC cell lines Hep3B, Bel-7402, HepG2 and SMMC-7721 were purchased from the Type Culture Collection of Chinese Academy of Sciences (Shanghai, China). These cells were cultured in Dulbecco's modified Eagle's medium (Invitrogen; Thermo Fisher Scientific, Inc., Waltham, MA, USA) supplemented with $10 \%$ fetal bovine serum (Sigma-Aldrich; Merck Millipore), 100 U/ml penicillin and $100 \mu \mathrm{g} / \mathrm{ml}$ streptomycin under standard incubation conditions $\left(37^{\circ} \mathrm{C}\right.$ and $\left.5 \% \mathrm{CO}_{2}\right)$.

Cytotoxicity assay based on the release of lactate dehydrogenase (LDH) and apoptosis analysis by flow cytometry. Following treatment, cell death was quantitatively detected by a cytotoxicity assay based on the release of LDH using a cytotoxicity detection kit (Promega Corporation, Madison, WI, USA) as described previously (34). All the experiments were repeated 3-5 times and data were expressed as the mean \pm standard deviation (SD). Flow cytometry was applied to detect apoptosis in cultured cells by using an Annexin V-FITC Apoptosis Detection kit purchased from Nanjing KeyGen Biotech Co., Ltd. (Nanjing, China). Cells were double stained with Annexin V-fluorescein isothiocyanate (FITC) and propidium iodide (PI). Apoptosis was then analyzed by flow cytometry (BD Biosciences). Early apoptotic cells with exposed phosphatidylserine but intact cell membranes bind Annexin V-FITC but exclude PI, and will be reported in the lower right-hand quadrant (B4). Necrotic or apoptotic cells in terminal stages will be both Annexin V-FITC and PI positive, and will be reported in the upper right-hand quadrant (B2).

Western blotting. Whole cell lysates were prepared by lysing cells in M2 buffer [20 mmol/1 Tris- $\mathrm{HCl}$ (pH 7.6), 0.5\% NP40, $250 \mathrm{mmol} / \mathrm{l} \mathrm{NaCl}, 3 \mathrm{mmol} / \mathrm{l}$ EDTA, $3 \mathrm{mmol} / \mathrm{l}$ ethylene glycol-bis( $\beta$-aminoethyl ether)-N,N,N',N'-tetraacetic acid, $2 \mathrm{mmol} / 1$ dithiothreitol, $0.5 \mathrm{mmol} / 1$ phenylmethylsulfonyl fluoride, $20 \mathrm{mmol} / 1 \beta$-glycerophosphate, $1 \mathrm{mmol} / 1$ sodium vanadate and $1 \mu \mathrm{g} / \mathrm{ml}$ leupeptin]. The concentration of proteins in the cell lysates was quantified by Bio-Rad Protein Assay (Bio Rad Laboratories, Inc., Hercules, CA, USA). Cell lysates $(\sim 50 \mu \mathrm{g})$ were resolved by SDS-PAGE (( $8 \%$ for detecting PARP, $10 \%$ for detecting p62 and $\beta$-actin, and $15 \%$ for detecting LC3B), transferred to a polyvinylidene fluoride membrane and detected with various antibodies: Anti-PARP (1:500; overnight at $\left.4^{\circ} \mathrm{C}\right)$; anti-p62 $\left(1: 1,000\right.$; overnight at $\left.4^{\circ} \mathrm{C}\right)$; anti- $\beta$-actin $(1: 5,000 ; 1 \mathrm{~h}$ at room temperature); and anti-LC3B $\left(1: 1,000\right.$; overnight at $\left.4^{\circ} \mathrm{C}\right)$. Subsequently, the membrane was washed three times for 5 min each with TBS containing Tween-20. Next, peroxidase-conjugated goat anti-mouse immunoglobulin (Ig)G (catalog no. ZB 2305; Beijing Zhongshan Golden Bridge Biotechnology Co., Ltd., Beijing, China) and peroxidase-conjugated goat anti-rabbit IgG (catalog no. ZB 2301; Beijing Zhongshan Golden Bridge Biotechnology Co., Ltd.) were added at a 1:5,000 dilution and incubated with the membrane at room temperature for $30 \mathrm{~min}$. The specific proteins were visualized by enhanced chemiluminescence (EMD Millipore, Billerica, MA, USA) using Image Lab ${ }^{\mathrm{TM}}$ 

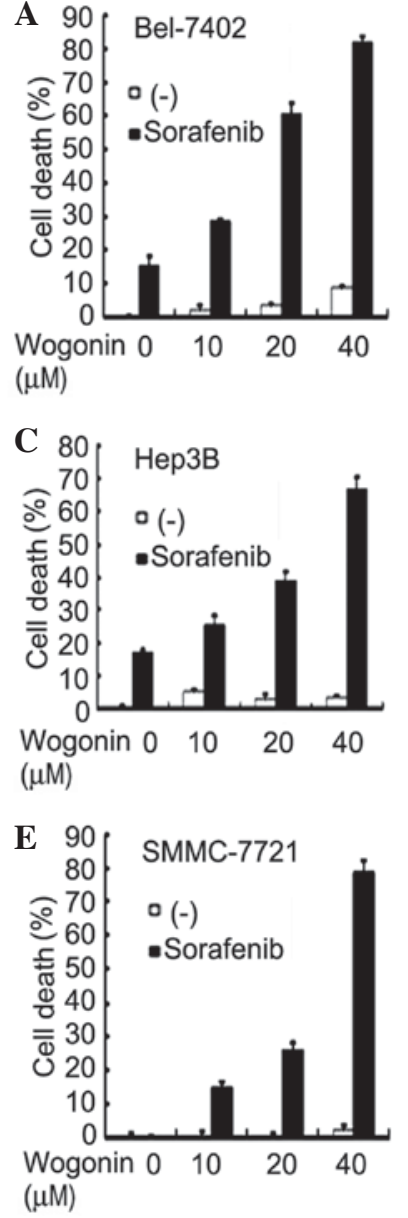

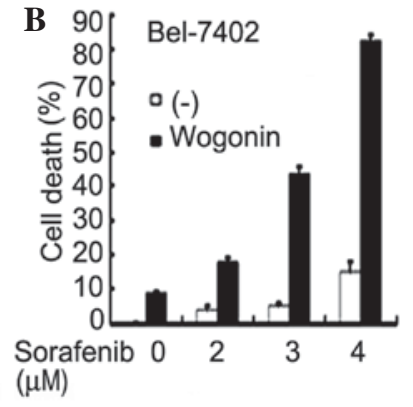

D
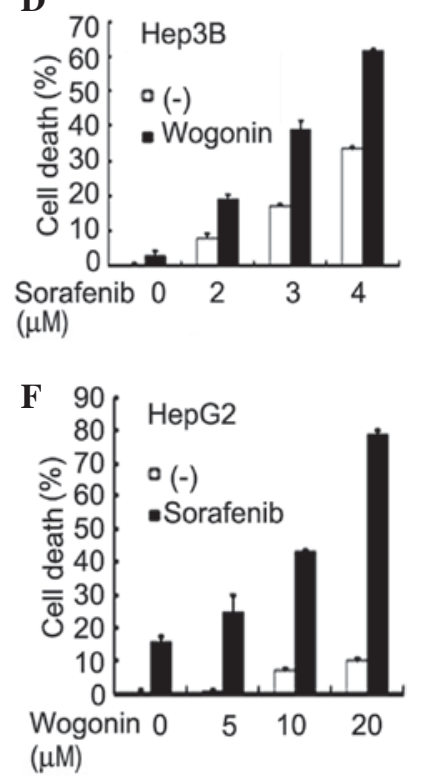

Figure 1. Combined treatment of sorafenib and wogonin induces synergistic cytotoxicity in human hepatocellular carcinoma cells. Cell death was determined by lactate dehydrogenase release assay. (A) Bel-7402 cells were treated with increasing concentrations of wogonin $(10-40 \mu \mathrm{M})$ or a fixed concentration of sorafenib $(4 \mu \mathrm{M})$ alone or in combination for $72 \mathrm{~h}$. (B) Bel-7402 cells were treated with a fixed concentration of wogonin $(40 \mu \mathrm{M})$ or increasing concentrations of sorafenib $(2-4 \mu \mathrm{M})$ alone or in combination for $72 \mathrm{~h}$. (C) Hep3B cells were treated with increasing concentrations of wogonin $(10-40 \mu \mathrm{M})$ or a fixed concentration of sorafenib $(3 \mu \mathrm{M})$ alone or in combination for $72 \mathrm{~h}$. (D) Hep3B cells were treated with a fixed concentration of wogonin $(20 \mu \mathrm{M})$ or increasing concentrations of sorafenib (2-4 $\mu \mathrm{M})$ alone or in combination for $72 \mathrm{~h}$. (E) SMMC-7721 cells were treated with increasing concentrations of wogonin $(10-40 \mu \mathrm{M})$ or a fixed concentration of sorafenib $(4 \mu \mathrm{M})$ alone or in combination for $72 \mathrm{~h}$. (F) HepG2 cells were treated with increasing concentrations of wogonin $(5-20 \mu \mathrm{M})$ or a fixed concentration of sorafenib $(4 \mu \mathrm{M})$ alone or in combination for $72 \mathrm{~h}$. Columns, mean of three experiments; bars, standard deviation; (-), untreated control.

station (Bio-Rad Laboratories, Inc.). Each experiment was repeated at $\geq 3$ times and representative results are shown.

Statistical analysis. Data are expressed as the mean \pm SD. Statistical significance was examined by paired Student's $t$ test using SPSS version 21.0 software (IBM Corp., Armonk, NY, USA). $\mathrm{P}<0.05$ was considered to indicate a statistically significant difference.

\section{Results}

Combined treatment of sorafenib and wogonin induces synergistic cytotoxicity in human HCC cells. To investigate

Table I. Synergistic interaction of sorafenib and wogonin in human hepatocellular carcinoma cells.

\begin{tabular}{lcc} 
A, Bel-7402 & \\
\hline Sorafenib $(\mu \mathrm{mol} / \mathrm{l})$ & Wogonin $(\mu \mathrm{mol} / \mathrm{l})$ & $\mathrm{CI}$ \\
\hline 2 & 40 & 0.781 \\
3 & 40 & 0.457 \\
4 & 40 & 0.225 \\
4 & 10 & 0.643 \\
4 & 20 & 0.351 \\
\hline & & \\
B, Hep3B & & $\mathrm{CI}$ \\
\hline Sorafenib $(\mu \mathrm{mol} / \mathrm{l})$ & Wogonin $(\mu \mathrm{mol} / \mathrm{l})$ & 0.691 \\
\hline 2 & 20 & 0.663 \\
3 & 20 & 0.640 \\
4 & 20 & 0.873 \\
3 & 10 & 0.448 \\
3 & 40 & \\
\hline
\end{tabular}

\section{C, SMMC-7721}

\begin{tabular}{lcc}
\hline Sorafenib $(\mu \mathrm{mol} / \mathrm{l})$ & Wogonin $(\mu \mathrm{mol} / \mathrm{l})$ & $\mathrm{CI}$ \\
\hline 2 & 20 & 0.223 \\
4 & 20 & 0.057 \\
6 & 20 & 0.003 \\
4 & 10 & 0.153 \\
\hline
\end{tabular}

\section{D, HepG2}

\begin{tabular}{lcc}
\hline Sorafenib $(\mu \mathrm{mol} / \mathrm{l})$ & Wogonin $(\mu \mathrm{mol} / \mathrm{l})$ & CI \\
\hline 4 & 5 & 0.985 \\
4 & 10 & 0.895 \\
4 & 20 & 0.683
\end{tabular}

The combination effect of sorafenib with wogonin was quantitatively evaluated using CI analysis. Briefly, CI is defined by the isobolar association $\mathrm{CI}=(\mathrm{a} / \mathrm{A})+(\mathrm{b} / \mathrm{B})$, where $\mathrm{a}$ and $\mathrm{b}$ are the doses of chemicals 1 and 2 used in combination to achieve a certain percentage of drug effect, and A and B are the doses of the chemicals that applied singly produce the same effect. $\mathrm{CI}<1,=1$ and $>1$ indicate synergism, additive effect and antagonism, respectively. CI was calculated for combined treatment with the indicated concentrations of sorafenib and wogonin. CI, combination index.

whether wogonin is able to enhance the anticancer activity of sorafenib, Bel-7402 cells were first treated with increasing concentrations of wogonin $(10-40 \mu \mathrm{M})$ and a fixed concentration of sorafenib $(4 \mu \mathrm{M})$, and cell death was measured by LDH release assay. The results indicated that, while sorafenib alone caused $<20 \%$ cell death and wogonin had little cytotoxicity, wogonin sensitized Bel-7402 cells to sorafenib-induced cell 

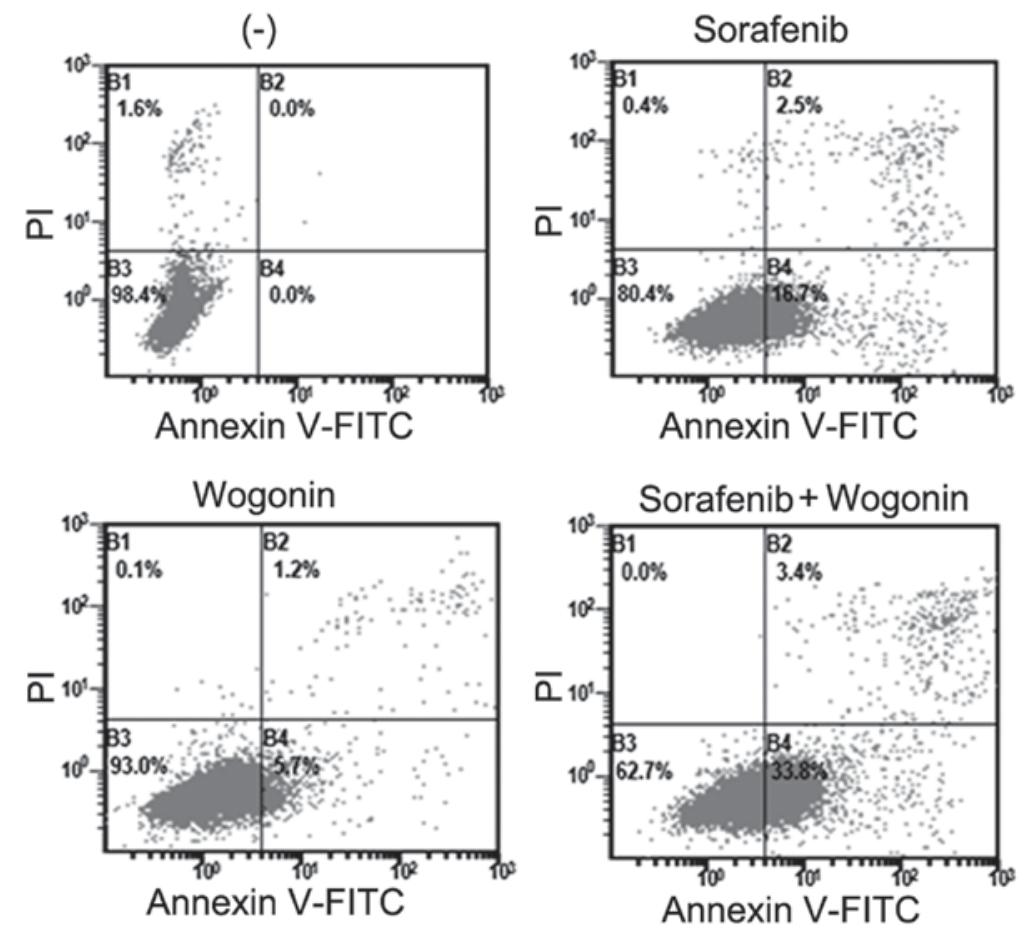

Figure 2. Apoptotic cells are significantly increased following sorafenib and wogonin co-treatment in hepatocellular carcinoma cells. Hep3B cells were treated with sorafenib $(4 \mu \mathrm{M})$ or wogonin $(20 \mu \mathrm{M})$ alone or in combination for $48 \mathrm{~h}$. The cells were then stained with Annexin V-FITC and PI, followed by flow cytometry analysis. The percentages of cell population in B1, B2 (late-stage apoptotic and necrotic cells), B3 (viable cells) and B4 (early apoptotic cells) are shown. (-), untreated control; FITC, fluorescein isothiocyanate; PI, propidium iodide.

death in a dose-dependent manner (Fig. 1A). Approximately $80 \%$ of the cells were killed at the highest dose of wogonin used $(40 \mu \mathrm{M})$, a concentration at which wogonin alone caused little cell death $(<10 \%)$. The combined cytotoxic effect of wogonin and sorafenib was synergistic, as evaluated by combination index analysis as described previously (35) (Table I). A similar dose-dependent potentiation of cytotoxicity was detected when increasing concentrations of sorafenib $(2-4 \mu \mathrm{M})$ with a fixed wogonin dose $(40 \mu \mathrm{M})$ were used (Fig. 1B). The sensitization of sorafenib's anticancer activity by wogonin was validated in other human HCC cell lines. In Hep3B cells, a similar dose-dependent synergism with fixed concentration of either sorafenib or wogonin was observed (Fig. 1C and D). Consistently, wogonin sensitized HepG2 and SMMC-7721 cells to sorafenib-induced cell death (Fig. 1E and F). These results suggest that the combination of wogonin and sorafenib is effective in sensitizing HCC cells to sorafenib-induced cytotoxicity.

The potentiated cytotoxicity induced by sorafenib and wogonin combination is achieved through apoptosis potentiation. As both wogonin and sorafenib can induce apoptosis, it was hypothesized that the enhanced cell death observed in wogonin and sorafenib co-treatment was achieved through potentiation of apoptosis. Hep3B cells were treated with sorafenib in the absence or presence of wogonin, and apoptosis was analyzed by Annexin V-FITC and PI staining followed by flow cytometric assay. Both early (B4) and late (B2) apoptotic cells were significantly increased upon sorafenib and wogonin co-treatment (Fig. 2). The cleavage of the caspase- 3 substrate PARP, which is a marker of

A

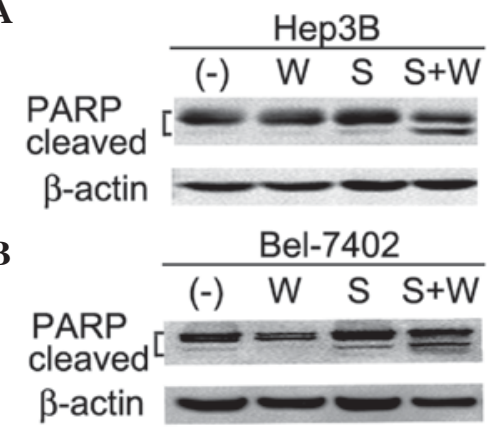

C

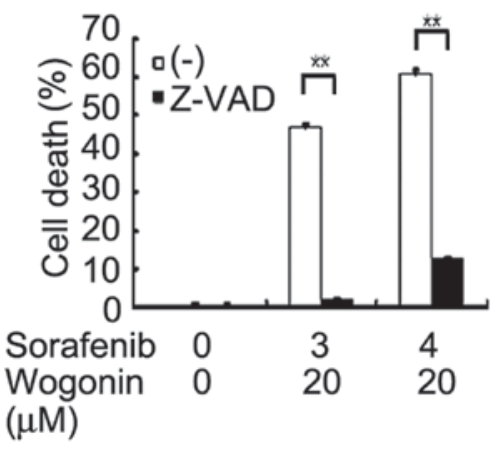

Figure 3. Activation of the apoptotic pathway is potentiated in sorafenib and wogonin co-treated hepatocellular carcinoma cells. (A) Hep3B and (B) Bel-7402 cells were treated with sorafenib $(4 \mu \mathrm{M})$ or wogonin $(20 \mu \mathrm{M})$ alone or in combination for $36 \mathrm{~h}$. PARP was detected by western blotting. $\beta$-actin was used as a control. (C) Hep3B cells were pretreated with Z-VAD $(20 \mu \mathrm{M})$ for $30 \mathrm{~min}$ or remained untreated, and then treated with sorafenib ( 3 or $4 \mu \mathrm{M}$ ) and wogonin $(20 \mu \mathrm{M})$ for $72 \mathrm{~h}$. Cell death was determined by lactate dehydrogenase release assay. Columns, mean of three experiments; bars, standard deviation. ${ }^{* *} \mathrm{P}<0.01$. (-), untreated control; S, sorafenib; W, wogonin; PARP, poly (ADP-ribose) polymerase; Z-VAD, carbobenzoxyvalyl-alanyl-aspartyl. 
A

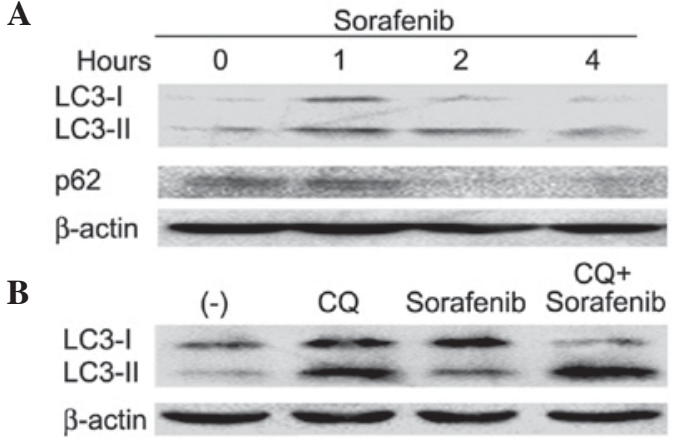

Figure 4. Sorafenib induces autophagy in hepatocellular carcinoma cells (A) Bel-7402 cells were treated with $4 \mu \mathrm{M}$ sorafenib for the indicated times. LC 3 and p 62 were detected by western blotting. $\beta$-actin was used as a control. (B) Bel-7402 cells were pretreated with CQ $(20 \mu \mathrm{M})$ or remained untreated and then treated with sorafenib $(4 \mu \mathrm{M})$ for $2 \mathrm{~h}$. LC3 was detected by western blotting. $\beta$-actin was used as a control. (-), untreated control; LC3, light chain 3 ; $\mathrm{CQ}$, chloroquine.

A

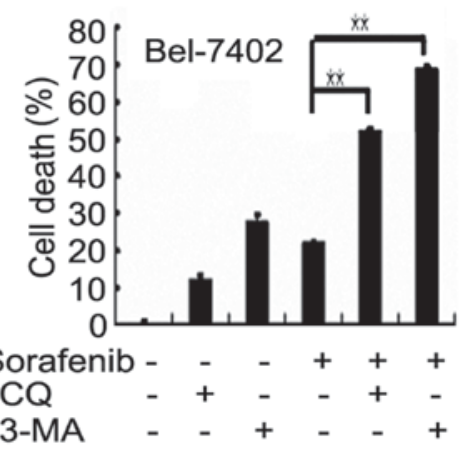

B

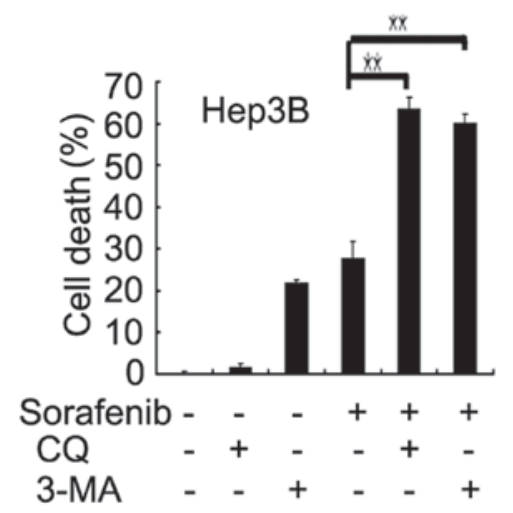

Figure 5. Autophagy induced by sorafenib is cytoprotective in hepatocellular carcinoma cells. (A) Bel-7402 and (B) Hep3B cells were pretreated with CQ $(20 \mu \mathrm{M})$ or 3 -MA $(10 \mathrm{mM})$ for $30 \mathrm{~min}$ or remained untreated. Then, the cells were treated with sorafenib $(4 \mu \mathrm{M})$ for $72 \mathrm{~h}$. Cell death was determined by lactate dehydrogenase release assay. Columns, mean of three experiments; bars, standard deviation. ${ }^{* *} \mathrm{P}<0.01$. CQ, chloroquine; 3-MA, 3-methyladenine.

apoptotic pathway activation, was increased in co-treated Hep3B and Bel-7402 cells, as detected by western blotting (Fig. 3A and B). Additionally, the pan-caspase inhibitor Z-VAD significantly suppressed the enhanced cytotoxicity induced by co-treatment with sorafenib and wogonin in Hep3B and Bel-7402 cells (Fig. 3C and data not shown, respectively). These results suggest that the enhanced cytotoxicity induced by sorafenib and wogonin combination was due to potentiation of apoptosis.

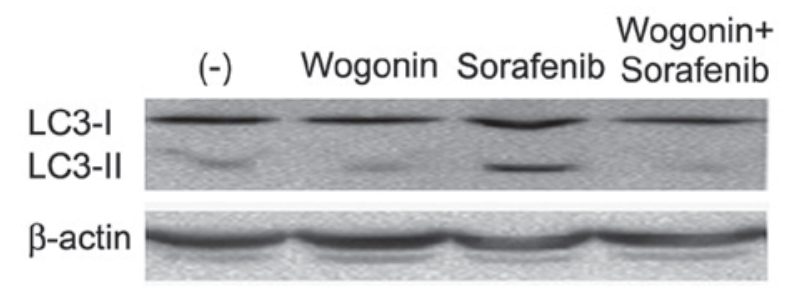

Figure 6. Wogonin inhibits sorafenib-induced cytoprotective autophagy and sensitizes cells to cytotoxicity. Bel-7402 cells were treated with sorafenib $(4 \mu \mathrm{M})$ or wogonin $(20 \mu \mathrm{M})$ alone or in combination for $2 \mathrm{~h}$. LC3 was detected by western blotting. $\beta$-actin was used as a control. (-), untreated control; LC3, light chain 3.

Wogonin inhibits sorafenib-induced cytoprotective autophagy and sensitizes cells to cytotoxicity. As sorafenib activates autophagy and the latter can either activate or suppress apoptosis, it was further investigated if autophagy is involved in the synergistic cytotoxity of sorafenib and wogonin. Sorafenib induced autophagy, which was shown as increased expression of LC3-II and decreased expression of p62, two autophagy hallmarks (Fig. 4A), in addition to autophagic flux (Fig. 4B). The role of sorafenib-induced autophagy was determined to be cytoprotective, since suppression of autophagy with two different autophagy inhibitors, CQ and 3-MA, remarkably increased sorafenib-induced cell death in both Bel-7402 and Hep3B cells (Fig. 5A and B). Next, the effect of wogonin on sorafenib-induced autophagy was examined. Wogonin effectively inhibited sorafenib-induced autophagy, which was shown as suppression of sorafenib-induced LC3-II expression (Fig. 6). Therefore, these data demonstrate that wogonin likely potentiated sorafenib-induced cell death through inhibiting autophagy.

\section{Discussion}

The present study first determined that sorafenib and wogonin combination is effective in killing multiple human HCC cell types. Enhanced cell death in co-treated cells was accompanied by potentiation of apoptosis. Furthermore, it was confirmed that sorafenib induced cytoprotective autophagy in HCC cells. Notably, wogonin also inhibited sorafenib-induced autophagy. Thus, potentiation of apoptosis and inhibition of sorafenib-induced protective autophagy may contribute to the enhanced cancer cell death caused by sorafenib and wogonin combination.

Wogonin is a candidate anticancer agent, which was shown to exert an apoptotic effect in tumor cells but has no obvious toxicity in normal cells $(36,37)$. Besides combination with classic DNA damaging agents for cancer therapy, it is of great interest to investigate if wogonin can be combined with targeted-therapy agents. The present study demonstrated for the first time that the combination of wogonin and sorafenib effectively kills human HCC cells, suggesting that wogonin could be an ideal candidate for increasing sorafenib's activity in HCC therapy, which warrants further in vivo investigation.

Apoptosis activation is one of the major mechanism underlying the anticancer activity of chemotherapeutics. The present study clearly demonstrated that the combination of sorafenib and wogonin cooperatively promoted apoptosis, which is at 
least one of the mechanism for enhanced anticancer activity. The mechanism by which sorafenib-induced apoptosis is promoted by wogonin deserves further study.

Previous studies have shown that sorafenib induces autophagy in multiple cancer cell types, which could be cytoprotective or cytotoxic, thus suppressing or promoting the anticancer activity of sorafenib (13-18). The autophagy induced by sorafenib in our experimental system was clearly determined to be cytoprotective in both Bel-7402 and Hep3B cells. As wogonin effectively blocked sorafenib-induced autophagy, it is likely that blocking cytoprotective autophagy underlies another mechanism of the enhanced cancer cell death caused by sorafenib and wogonin combination.

Taken together, the present study is the first to report that wogonin sensitizes sorafenib's anti-HCC activity, which is associated with apoptosis potentiation and autophagy inhibition. Sorafenib and wogonin combination may be an ideal approach for increasing sorafenib's anticancer activity, which warrants further in vivo investigation.

\section{Acknowledgements}

The present study was supported by grants from the National Natural Science Foundation of China (grant nos. 81172111 and 81372377) and the Science \& Technology Department of Sichuan Province, China (grant no. 2015JY0096).

\section{References}

1. Wilhelm S, Carter C, Lynch M, Lowinger T, Dumas J, Smith RA, Schwartz B, Simantov R and Kelley S: Discovery and development of sorafenib: A multikinase inhibitor for treating cancer. Nat Rev Drug Discov 5: 835-844, 2006.

2. Liu L, Cao Y, Chen C, Zhang X, McNabola A, Wilkie D, Wilhelm S, Lynch $M$ and Carter C. Sorafenib blocks the RAF/MEK/ERK pathway, inhibits tumor angiogenesis, and induces tumor cell apoptosis in hepatocellular carcinoma model PLC/PRF/5. Cancer Res 66: 11851-11858, 2006.

3. Llovet JM, Ricci S, Mazzaferro V, Hilgard P, Gane E, Blanc JF, de Oliveira AC, Santoro A, Raoul JL, Forner A, et al; SHARP Investigators Study Grou: Sorafenib in advanced hepatocellular carcinoma. N Engl J Med 359: 378-390, 2008.

4. Cheng AL, Kang YK, Chen Z, Tsao CJ, Qin S, Kim JS, Luo R, Feng J, Ye S, Yang TS, et al: Efficacy and safety of sorafenib in patients in the Asia-Pacific region with advanced hepatocellular carcinoma: A phase III randomised, double-blind, placebo-controlled trial. Lancet Oncol 10: 25-34, 2009.

5. Kane RC, Farrell AT, Saber H, Tang S, Williams G, Jee JM, Liang C, Booth B, Chidambaram N, Morse D, et al: Sorafenib for the treatment of advanced renal cell carcinoma. Clin Cancer Res 12: 7271-7278, 2006.

6. Keating GM and Santoro A: Sorafenib: A review of its use in advanced hepatocellular carcinoma. Drugs 69: 223-240, 2009.

7. Gauthier A and Ho M: Role of sorafenib in the treatment of advanced hepatocellular carcinoma: An update. Hepatol Res 43: 147-154, 2013.

8. Levine B and Klionsky DJ: Development by self-digestion: Molecular mechanisms and biological functions of autophagy. Dev Cell 6: 463-477, 2004.

9. Czaja MJ, Ding WX, Donohue TM Jr., Friedman SL, Kim JS, Komatsu M, Lemasters JJ, Lemoine A, Lin JD, Ou JH, et al: Functions of autophagy in normal and diseased liver. Autophagy 9: 1131-1158, 2013.

10. Kondo Y, Kanzawa T, Sawaya R and Kondo S: The role of autophagy in cancer development and response to therapy. Nat Rev Cancer 5: 726-734, 2005.

11. Ding ZB, Hui B, Shi YH, Zhou J, Peng YF, Gu CY, Yang H, Shi GM, Ke AW, Wang XY, et al: Autophagy activation in hepatocellular carcinoma contributes to the tolerance of oxaliplatin via reactive oxygen species modulation. Clin Cancer Res 17: 6229-6238, 2011.
12. Luo T, Fu J, Xu A, Su B, Ren Y, Li N, Zhu J, Zhao X, Dai R, Cao J, et al: PSMD10/gankyrin induces autophagy to promote tumor progression through cytoplasmic interaction with ATG7 and nuclear transactivation of ATG7 expression. Autophagy 12: 1355-1371, 2016.

13. Shimizu S, Takehara T, Hikita H, Kodama T, Tsunematsu H, Miyagi T, Hosui A, Ishida H, Tatsumi T, Kanto T, et al: Inhibition of autophagy potentiates the antitumor effect of the multikinase inhibitor sorafenib in hepatocellular carcinoma. Int J Cancer 131: 548-557, 2012.

14. Shi YH, Ding ZB, Zhou J, Hui B, Shi GM, Ke AW, Wang XY, Dai Z, Peng YF, Gu CY, et al: Targeting autophagy enhances sorafenib lethality for hepatocellular carcinoma via ER stress-related apoptosis. Autophagy 7: 1159-1172, 2011.

15. Park MA, Zhang G, Martin AP, Hamed H, Mitchell C, Hylemon PB, Graf M, Rahmani M, Ryan K, Liu X, et al: Vorinostat and sorafenib increase ER stress, autophagy and apoptosis via ceramide-dependent CD95 and PERK activation. Cancer Biol Ther 7: 1648-1662, 2008.

16. Tai WT, Shiau CW, Chen HL, Liu CY, Lin CS, Cheng AL, Chen PJ and Chen KF: Mcl-1-dependent activation of Beclin 1 mediates autophagic cell death induced by sorafenib and SC-59 in hepatocellular carcinoma cells. Cell Death Dis 4: e485, 2013.

17. Lin CI, Whang EE, Lorch JH and Ruan DT: Autophagic activation potentiates the antiproliferative effects of tyrosine kinase inhibitors in medullary thyroid cancer. Surgery 152: 1142-1149, 2012.

18. Bareford MD, Hamed HA, Tang Y, Cruickshanks N, Burow ME, Fisher PB, Moran RG, Nephew KP, Grant S and Dent P: Sorafenib enhances pemetrexed cytotoxicity through an autophagy-dependent mechanism in cancer cells. Autophagy 7 : 1261-1262, 2011.

19. Sajithlal GB, Hamed HA, Cruickshanks N, Booth L, Tavallai S, Syed J, Grant S, Poklepovic A and Dent P: Sorafenib/regorafenib and phosphatidyl inositol 3 kinase/thymoma viral proto-oncogene inhibition interact to kill tumor cells. Mol Pharmacol 84: 562-571, 2013.

20. Grignani G, Palmerini E, Ferraresi V, D'Ambrosio L, Bertulli R, Asaftei SD, Tamburini A, Pignochino Y, Sangiolo D, Marchesi E, et al; Italian Sarcoma Group: Sorafenib and everolimus for patients with unresectable high-grade osteosarcoma progressing after standard treatment: A non-randomised phase 2 clinical trial. Lancet Oncol 16: 98-107, 2015.

21. Flaherty KT, Lee SJ, Zhao F, Schuchter LM, Flaherty L, Kefford R, Atkins MB, Leming P and Kirkwood JM: Phase III trial of carboplatin and paclitaxel with or without sorafenib in metastatic melanoma. J Clin Oncol 31: 373-379, 2012.

22. Paz-Ares LG, Biesma B, Heigener D, von Pawel J, Eisen T, Bennouna J, Zhang L, Liao M, Sun Y, Gans S, et al; NSCLC [non-small-cell lung cancer] Research Experience Utilizing Sorafenib (NExUS) Investigators Study Group: Phase III, randomized, double-blind, placebo-controlled trial of gemcitabine/cisplatin alone or with sorafenib for the first-line treatment of advanced, nonsquamous non-small-cell lung cancer. J Clin Oncol 30: 3084-3092, 2012.

23. Banerjee S, Wang Z, Kong D and Sarkar FH: 3,3'-Diindolylmethane enhances chemosensitivity of multiple chemotherapeutic agents in pancreatic cancer. Cancer Res 69: 5592-5600, 2009.

24. Turrini E, Ferruzzi L and Fimognari C: Natural compounds to overcome cancer chemoresistance: Toxicological and clinical issues. Expert Opin Drug Metab Toxicol 10: 1677-1690, 2014.

25. Fas SC, Baumann S, Zhu JY, Giasi M, Treiber MK, Mahlknecht U, Krammer PH and Li-Weber M: Wogonin sensitizes resistant malignant cells to TNF- and TRAIL-induced apoptosis. Blood 108: 3700-3706, 2007.

26. Zhao Y, Li H, Gao Z, Gong $\mathrm{Y}$ and $\mathrm{Xu} \mathrm{H}$ : Effects of flavonoids extracted from Scutellaria baicalensis Georgi on hemin-nitrite- $\mathrm{H}_{2} \mathrm{O}_{2}$ induced liver injury. Eur J Pharmacol 536: 192-199, 2006

27. Ma SC, Du J, But PP, Deng XL, Zhang YW, Ooi VE, Xu HX, Lee SH and Lee SF: Antiviral Chinese medicinal herbs against respiratory syncytial virus. J Ethnopharmacol 79: 205-211, 2002.

28. Kimura Y, Okuda H and Ogita Z: Effects of flavonoids isolated from Scutellariae radix on fibrinolytic system induced by trypsin in human umbilical vein endothelial cells. J Nat Prod 60: 598-601, 1997.

29. Chi YS, Lim H, Park H and Kim HP: Effects of wogonin, a plant flavone from Scutellaria radix, on skin inflammation: In vivo regulation of inflammation-associated gene expression. Biochem Pharmacol 66: 1271-1278, 2003. 
30. Polier G, Ding J, Konkimalla BV, Eick D, Ribeiro N, Köhler R, Giaisi M, Efferth T, Desaubry L, Krammer PH and Li-Weber M: Wogonin and related natural flavones are inhibitors of CDK9 that induce apoptosis in cancer cells by transcriptional suppression of Mcl-1. Cell Death Dis 2 :e182, 2011.

31. Chung H, Jung YM, Shin DH, Lee JY, Oh MY, Kim HJ, Jang KS, Jeon SJ, Son KH and Kong G: Anticancer effects of wogonin in both estrogen receptor-positive and -negative human breast cancer cell lines in vitro and in nude mice xenografts. Int J Cancer 122: 816-822, 2008

32. He F, Wang Q, Zheng XL, Yan JQ, Yang L, Sun H, Hu LN, Lin Y and Wang X: Wogonin potentiates cisplatin-induced cancer cell apoptosis through accumulation of intracellular reactive oxygen species. Oncol Rep 28: 601-605, 2012.

33. Lee E, Enomoto R, Koshiba C and Hirano H: Inhibition of P-glycoprotein by wogonin is involved with the potentiation of etoposide-induced apoptosis in cancer cells. Ann N Y Acad Sci 1171: 132-136, 2009.
34. Wang X, Ju W, Renouard J, Aden J, Belinsky SA and Lin Y: 17-Allylamino-17-demethoxygeldanamycin synergistically potentiates tumor necrosis factor-induced lung cancer cell death by blocking the nuclear factor-kappaB pathway. Cancer Res 66: 1089-1095, 2006

35. Zhao L, Wientjes MG and Au JL: Evaluation of combination chemotherapy: Integration of nonlinear regression, curve shift, isobologram, and combination index analyses. Clin Cancer Res 10: 7994-8004, 2004.

36. Lee DH, Kim C, Zhang L and Lee YJ: Role of p53, PUMA, and Bax in wogonin-induced apoptosis in human cancer cells. Biochem Pharmacol 75: 2020-2033, 2008.

37. Baumann S, Fas SC, Giaisi M, Müller WW, Merling A, Gülow K, Edler L, Krammer PH and Li-Weber M: Wogonin preferentially kills malignant lymphocytes and suppresses T-cell tumor growth by inducing PLCgamma1- and $\mathrm{Ca}^{2+}$-dependent apoptosis Blood 111: 2354-2363, 2008. 